\title{
Phosphine/Sulfoxide-Supported Carbon(0) Complex
}

\author{
Mariana Lozano González, ${ }^{[a, b]}$ Laura Bousquet, ${ }^{[a]}$ Sophie Hameury, ${ }^{[a]}$ Cecilio Alvarez Toledano, ${ }^{[b]}$ \\ Nathalie Saffon-Merceron, ${ }^{[c]}$ Vicenç Branchadell, ${ }^{[\mathrm{d}]}{ }^{\mathrm{E}}$ Eddy Maerten ${ }^{*},{ }^{[\mathrm{a}]}$ and Antoine Baceiredo*[a]
}

\begin{abstract}
A new carbon(0) complex 2 with two different $L$ ligands, a phosphine and a sulfoxide, was synthesized and fully characterized. This new type of carbone exhibits excellent coordination ability, in contrast to the related phosphine/sulfide-supported carbon(0) complexes. Several organometallic complexes were isolated and, of special interest, the $v_{\text {av }}(\mathrm{CO})$ value of $\mathrm{Rh}(\mathrm{I})$-dicarbonyl complex indicates that $\mathbf{2}$ has a donor capability superior to classical NHCs.
\end{abstract}

The discovery of the first stable carbenes almost 30 years ago[1] has initiated intensive research leading to a deeper understanding of physical and chemical properties of these divalent species. ${ }^{[2]}$ As a consequence, stable carbenes rapidly became essential as synthetic tools, ${ }^{[3]}$ organocatalysts, ${ }^{[4]}$ and efficient ligands for transition-metal homogeneous catalysis. ${ }^{[5]}$ As represented by $\mathrm{N}$-heterocyclic carbenes (NHCs) I, the catalytic activity of the corresponding NHC-metal-complexes relies mainly on the electronic properties of $\mathbf{I}$ as strong electron-donating auxiliary ligands. The related divalent carbon(0) II species (also named carbones), bearing two lone pairs on the central carbon atom, discovered by Ramirez in the $60 \mathrm{~s},{ }^{\left[{ }^{[6]}\right.}$ were considered as such only very recently. Indeed, Frenking et al. have suggested that, based on their electronic structure and chemical behavior, these molecules are best described as a carbon atom in the oxidation state zero stabilized by two L-ligands. ${ }^{[7]}$ This vision has shed new light on this family of compounds encouraging the development of new carbon( 0 ) complexes by combining various types of L-ligands. ${ }^{[8]}$ It is well established that carbon(0) complexes such as cyclic carbodiphosphoranes (CDP) III, cyclic bent allenes IV and carbodicarbenes $\mathbf{V}$ present a powerful electron-donating ability, which is far stronger than that of classical NHCs I. ${ }^{[9]}$ Therefore, carbon(0) species have been used as ligands for the preparation of metal complexes ${ }^{[10]}$ showing interesting catalytic activities..$^{[11-14]}$ Although the robustness of the corresponding organometallics complexes still deserves improvement, their catalytic efficiency often surpass that observed with the related NHC-metal catalysts. Of particular interest, Stephen recently took advantage of the presence of the

[a] Dr. M. Lozano González, L. Bousquet, Dr. S. Hameury, Dr. E. Maerten, Dr. A. Baceiredo

Université de Toulouse, UPS, and CNRS, LHFA UMR 5069

118 route de Narbonne, 31062 Toulouse (France)

E-mail: baceired@chimie.ups-tlse.fr; maerten@chimie.ups-tlse.fr

[b] Dr. M. Lozano González, Prof. C. Alvarez Toledano, Instituto de Química-UNAM, Circuito Exterior, Ciudad Universitaria, Coyoacán C.P. 04510 Ciudad de México (México)

[c] Dr. N. Saffon-Merceron

Université de Toulouse, UPS, and CNRS, ICT FR2599

118 route de Narbonne, 31062 Toulouse

[d] Prof. V. Branchadell

Departament de Quimica, Universitat Autonoma de Barcelona 08193 Bellaterra (Spain)

Supporting information for this article is given via a link at the end of the document. second lone pair at the central carbon atom to stabilize electrondeficient organometallic complexes thus obtaining high activities for hydrogenation reactions. ${ }^{[15]}$ Alcarazo used the four electrondonor ability of carbodiphosphoranes II $\left(\mathrm{L}=\mathrm{PR}_{3}\right)$ to stabilize the highly reactive dihydroborenium ion $\left(\mathrm{BH}_{2}^{+}\right)^{[16]}$ Finally, Ong evidenced an unexpected $\pi$-accepting ability of carbodicarbenes V resulting in an ambiphilic-type reactivity, allowing the activation of small molecules. ${ }^{[17]}$

As a part of our program to design, synthesize and develop new carbon(0) complexes, we report here the synthesis and the characterization of a new phosphine/sulfoxide-supported carbon(0) complex $\mathbf{2}$ and its ability to act as an efficient ligand for the preparation of transition metal complexes.

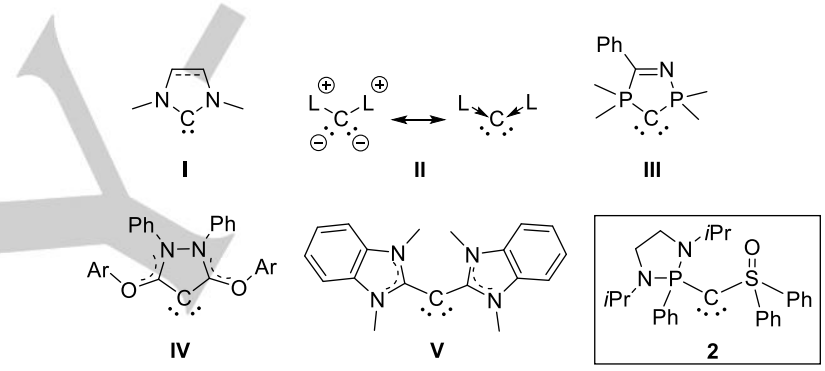

Figure 1. Carbenes and carbon( 0 ) complexes (for a better readability, formal charges were omitted in III, IV, $\mathbf{V}$ and $\mathbf{2}$.

The phosphine/sulfoxide carbon(0) complex 2 was prepared in two steps from the corresponding chlorophosphonium and methyldiphenylsulfoxonium salts in presence of 2 equivalents of a non-nucleophilic strong base (LDA) (Scheme 1). ${ }^{[18]}$ In a second step, the deprotonation of salt 1 was performed in THF solution at RT, either with potassium hydride $(\mathrm{KH})$ or potassium hexamethyldisilazane (KHMDS) leading to the selective formation of 2 , which was isolated in $69 \%$ overall yield.

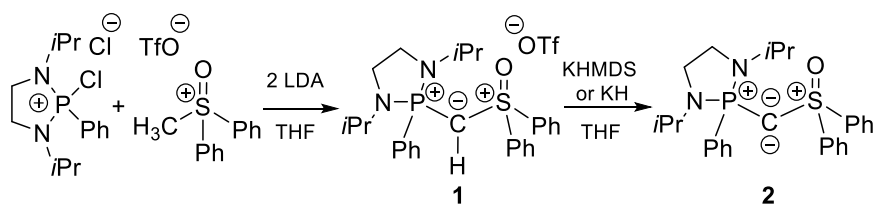

Scheme 1. Synthesis of ylide 1 and phosphine/sulfoxide carbon(0) complex 2

In the ${ }^{31} \mathrm{P}$ NMR spectrum, 2 displays a signal shifted to higher field (29.0 ppm) compared to 1 (45.0 ppm). The central carbon of 2 exhibits a doublet signal at $\delta=31.2 \mathrm{ppm}\left({ }^{1} \mathrm{JPC}=84.8\right.$ $\mathrm{Hz}$ ) with a large coupling constant in agreement with a direct $\mathrm{P}$ $C$ connectivity. The structures of both $\mathbf{1}$ and $\mathbf{2}$ were confirmed by 
X-Ray diffraction analysis (Figures 2 and 3). ${ }^{[19]}$ The P1-C1 bond length [1.6563(13) $\AA$ ] in 2 is significantly shorter than in $\mathbf{1}$ $[1.7190(15) \AA]$ and the value remains slightly longer than those reported for CDPs (1.584 - $1.648 \AA$ ). ${ }^{[20]}$ The S1-C1 bond length also undergoes significant shortening upon deprotonation [from $1.6539(15) \AA$ in 1 to $1.5929(14) \AA$ in 2], this value is the shortest S-C bond length reported to date in the sulfur-stabilized carbone series $(1.602-1.713 \AA){ }^{[8 c, h, 21]}$ The S1-O1, S1-C16, and S1-C22 bond lengths get slightly longer $\left(\Delta_{\mathrm{s}-\mathrm{x}} \max =+0.02 \AA\right)$. These data clearly indicate the delocalization of $\mathrm{p}_{\pi}$-lone pair at the carbon center toward sulfoxide ligand. Similarly to the case of carbodiphosphoranes, ${ }^{[7 a]}$ the P-C-S angle remains almost unchanged between the precursor 1 and carbone $2\left[120.98(9)^{\circ}\right.$ vs $120.74(8)^{\circ}$ respectively], and this value is in the range of those observed for iminosulfane/phosphine- or bis(iminosulfane)-carbones. ${ }^{[8 \mathrm{a}, \mathrm{h}]}$

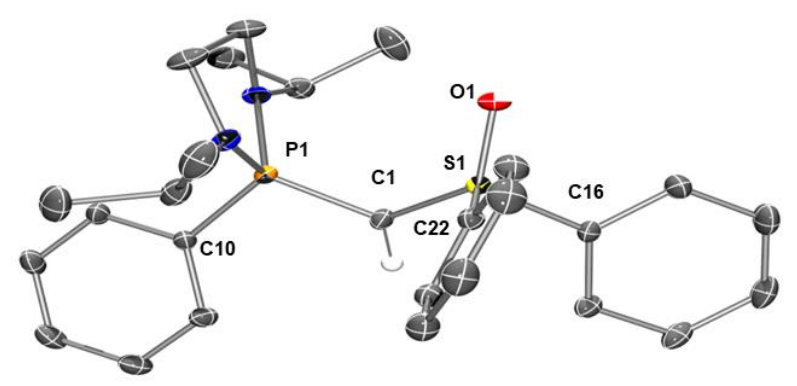

Figure 2. Molecular structure of 1. Thermal ellipsoids represent $30 \%$ probability. $\mathrm{H}$ atoms (except on $\mathrm{C} 1$ ) and counterion ( $\left.\mathrm{TfO}^{-}\right)$were omitted for clarity. Selected bond lengths $[\AA]$ and angles $\left[{ }^{\circ}\right]$ : S1-C1 1.6539(15), P1-C1 1.7190(15), S1-C16 1.7764(15), S1-C22 1.7771(16), P1-C10 1.7888(16), S1-O1 1.4531(12), S1-C1-P1 120.98(9).

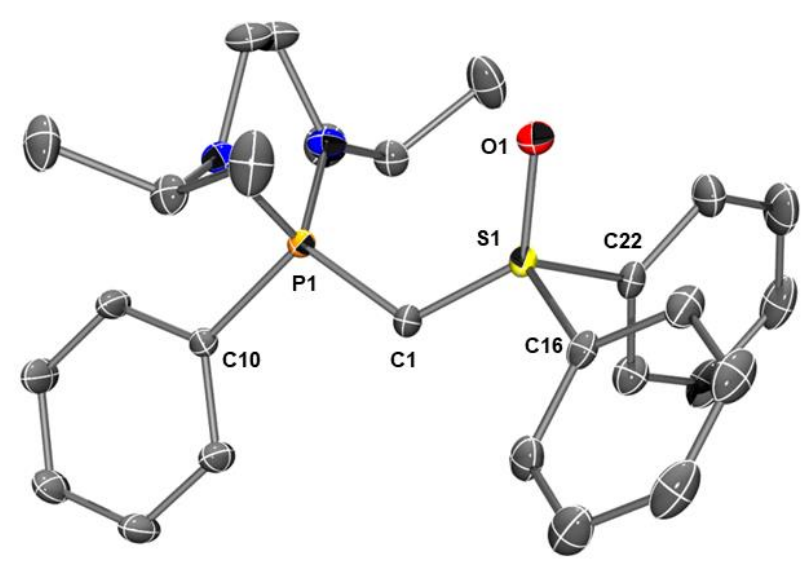

Figure 3. Molecular structure of 2. Thermal ellipsoids represent $30 \%$ probability. $\mathrm{H}$ atoms were omitted for clarity. Selected bond lengths $[\AA]$ and angles [ ${ }^{\circ}$ : S1-C1 1.5929(14), P1-C1 1.6563(13), S1-C16 1.7995(14), S1C22 1.7956(14), P1-C10 1.8083(13), S1-O1 1.4676(10), S1-C1P1 120.74(8).
To gain more insight into the electronic structures of $\mathbf{1}$ and 2. DFT calculation were performed at the M06-2X/6-31G(d) level of theory. The optimized geometries are consistent with the experimental X-Ray data (See Sup. Info for complete comparison). The variation of Wiberg bond indices ongoing from 1 to 2 (for P1-C1: +0.266 , C1-S1: +0.241 and S1-01: -0.089) correlates with the measurement obtained from the X-Ray data (for $\Delta \mathrm{P} 1-\mathrm{C} 1 \mathrm{:}-0.0627 \AA, \Delta \mathrm{C} 1-\mathrm{S} 1 \mathrm{t}:-0.0610 \AA$ and $\Delta \mathrm{S} 1-01$ : $+0.0145 \AA$ ). ${ }^{[22]}$ The central carbon atom in 2 bears a large negative charge $(-1.388)$ similarly to iminosulfane/phosphinecarbone (-1.38). ${ }^{[8 \mathrm{~h}]}$ The two highest occupied molecular orbitals $\left(\mathrm{HOMO}-1 \mathrm{n}_{\sigma \mathrm{C}}, \mathrm{HOMO} \mathrm{n}_{\pi \mathrm{C}}\right.$ ) correspond to the two lone pairs at the central carbon in 2 (Figure 4). The HOMO-1, the in-plane $\sigma$ lone pair, is partially deformed towards the sulfur atom of sulfoxide ligand, suggesting a negative hyperconjugaison $n_{\sigma \mathrm{C}} /$ $\sigma^{*}$ (S-C or S-O).

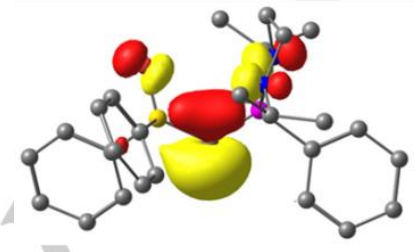

HOMO-1 (-6.76 eV)

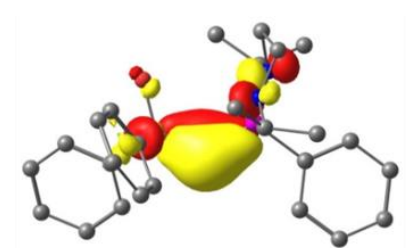

HOMO $(-6.37 \mathrm{eV})$
Figure 4. Calculated frontier orbitals of 2 at the M06-2X/6-31G(d) level of theory.

The nucleophilic character of $\mathbf{2}$ was experimentally confirmed by an immediate reaction with methyl iodide, giving raise to the corresponding C-methylated salt 3 . The ${ }^{31} \mathrm{P}$ NMR spectrum indicates a selective reaction with a unique signal at $\delta$ $=51.9 \mathrm{ppm}$. The methylation was confirmed by the presence of two characteristic doublets at $\delta=1.72 \mathrm{ppm}\left(J_{\mathrm{PH}}=12.5 \mathrm{~Hz}\right)$ and at $\delta=16.4\left(\mathrm{~d}, J_{\mathrm{CP}}=9.3 \mathrm{~Hz}\right)$ in the ${ }^{1} \mathrm{H}$ and ${ }^{13} \mathrm{C}$ NMR spectra respectively. Compound $\mathbf{3}$ was isolated in crystalline form and its structure was confirmed by X-Ray diffraction analysis (See Supporting Information). The molecular structure of $\mathbf{3}$ shows a significantly elongated S1-C1 bond $[1.6717(16) \AA]$ relative to that of $2[1.5929(14) \AA]$, which is in good agreement with the loss of one of the two lone pairs at the central carbon atom upon Cmethylation.

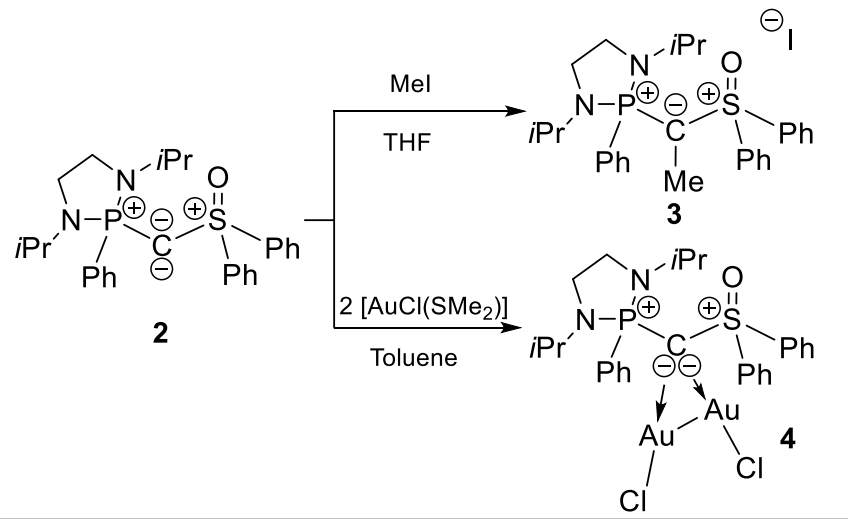


The potential usefulness of phosphine/sulfoxide-carbone 2 as ligand for transition metals was demonstrated by selective reaction with two equivalents of $\left[\mathrm{AuCl}\left(\mathrm{SMe}_{2}\right)\right]$ affording cleanly the neutral gem-aurated complex 4, in good yield (68\%). Similarly to carbodisphosphoranes and carbodicarbenes, ${ }^{[8 b, 23]}$ the formation of complex $\mathbf{4}$ demonstrates the ability of $\mathbf{2}$ to act as a four-electron donor ligand. In the ${ }^{31} \mathrm{P}$ NMR spectrum 4 displays a singlet signal at $\delta=41.2 \mathrm{ppm}$, while the central carbon atom appears as a doublet at $\delta=35.8 \mathrm{ppm}\left(J_{\mathrm{CP}}=47.5 \mathrm{~Hz}\right)$ in ${ }^{13} \mathrm{C}$ NMR spectrum. Complex 4 has been isolated as colorless crystals from a concentrated dichloromethane solution, and its structure was unambiguously confirmed by X-Ray diffraction analysis (Figure 5 ).

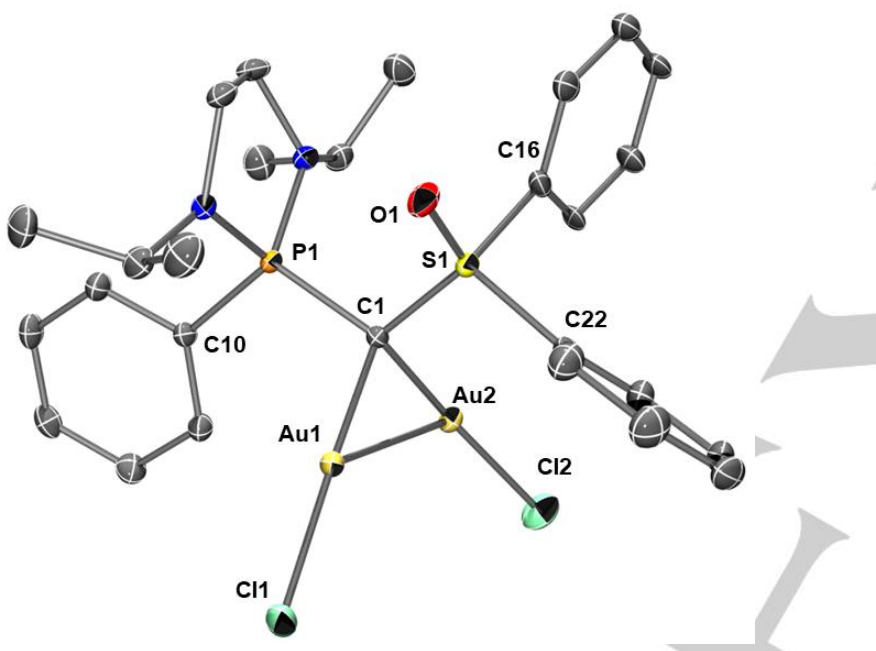

Figure 5. Molecular structure of 4. Thermal ellipsoids represent $30 \%$ probability. $\mathrm{H}$ and disordered atoms and solvent molecule (dichloromethane) were omitted for clarity. Selected bond lengths $[\AA]$ and angles $\left[{ }^{\circ}\right]$ : S1-C1 1.737(4), P1-C1 1.781(4), C1-Au1 2.071(4), C1-Au2 2.056(4), P1-C10 1.805(4), S1-C16 1.819(7), S1-C22 1.786(4), O1-S1 1.447(3), Au1-Au2 3.018(1), Au1-Cl1 2.287(1), Au2-Cl2 2.289(1), S1-C1-P1 110.2(2), P1C1-Au1 109.92(19), Au1-C1-Au2 93.99(15), C1-Au1-Au2 42.81(11), Au1-Au2-C1 43.20(11), C1-Au1-Cl1 176.22(11), C1-Au2-Cl2 172.52(11).

The C-Au bond lengths [2.056(4) and 2.071(4) A] are shorter than those observed in the related carbodisphosphorane- and carbodicarbene-diaurated complexes (2.074, 2.078 $\AA$ and 2.080, $2.103 \AA$ respectively). The aurophilic interaction is classical with Au1-Au2 distance of 3.018(1) $\AA$, which is in the range of other gem-diaurated carbones (2.952 $3.143 \AA$ A) ${ }^{[8 b, 8 h, 18 c, 20]}$ Finally, the P1-C1 [1.781(4) Å] and the S1C1 [1.737(4) $\AA$ ] bonds lengths are significantly longer than in $\mathbf{1}$, typical for single bonds (P-C : $1.79-1.82 \AA$ and S-C : $1.73-$ $1.75 \AA)^{[24]}$ confirming that the two lone pairs are involved in the formation of complex 4.

One established method for measuring the electron-donor ability of ligands is based on the carbonyl stretching frequencies of cis-[RhCl(CO) $\left.{ }_{2} \mathrm{~L}\right] \quad$ complexes. ${ }^{[25]}$ Therefore, phosphine/sulfoxide-carbone 2 was reacted with 0.5 equiv. of $[\mathrm{RhCl}(\mathrm{COD})]_{2}$, leading to the clean formation of rhodium(I) complex 5 as indicated by a doublet at $\delta=42.6 \mathrm{ppm}\left(\mathrm{d}, \mathrm{JPRh}_{\mathrm{PR}}=\right.$ $2.7 \mathrm{~Hz}$ ) in the ${ }^{31} \mathrm{P}$ spectrum. In the ${ }^{13} \mathrm{C}$ NMR spectrum, the central carbon atom appears at $\delta=16.3 \mathrm{ppm}$ as a doublet of doublet $\left(J_{\mathrm{CP}}=56.7 \mathrm{~Hz}, J_{\mathrm{CRh}}=37.5 \mathrm{~Hz}\right)$. Complex 5 is stable in solution at low temperature, but decomposes slowly at RT. The corresponding $\mathrm{Rh}(\mathrm{I})$ dicarbonyl complex 6 was prepared by bubbling carbon monoxide gas through a THF solution of 5 at $78{ }^{\circ} \mathrm{C}$ (Scheme 3). The formation of 6 was indicated by a color change from yellow to brown-red. The ${ }^{31} \mathrm{P}$ spectrum indicates a new doublet at $\delta=43.3 \mathrm{ppm}\left(\mathrm{J}_{\mathrm{PRh}}=2.3 \mathrm{~Hz}\right)$ and in the ${ }^{13} \mathrm{C} \mathrm{NMR}$ spectrum, the signal corresponding to the central carbon atom is relatively deshielded at $\delta=20.8 \mathrm{ppm}\left(\mathrm{J}_{\mathrm{CP}}=66.6 \mathrm{~Hz}, J_{\mathrm{CRh}}=33.0\right.$ $\mathrm{Hz}$ ) compared to $5^{[26]}$ The molecular structures of both complexes $\mathbf{5}$ and $\mathbf{6}$ were confirmed by X-ray diffraction analysis (Figures 6 and 7). In both complexes, P1-C1 [1.7070(14) ^ (5) and 1.709(2) $\AA$ (6)] and S1-C1 [1.6400(14) $\AA$ (5) and 1.654(2) $\AA$ (6)] bond lengths are very similar to those observed in $\mathbf{1}$ and 3 , meaning that only one lone pair of the central carbon atom interacts with the Rh center.

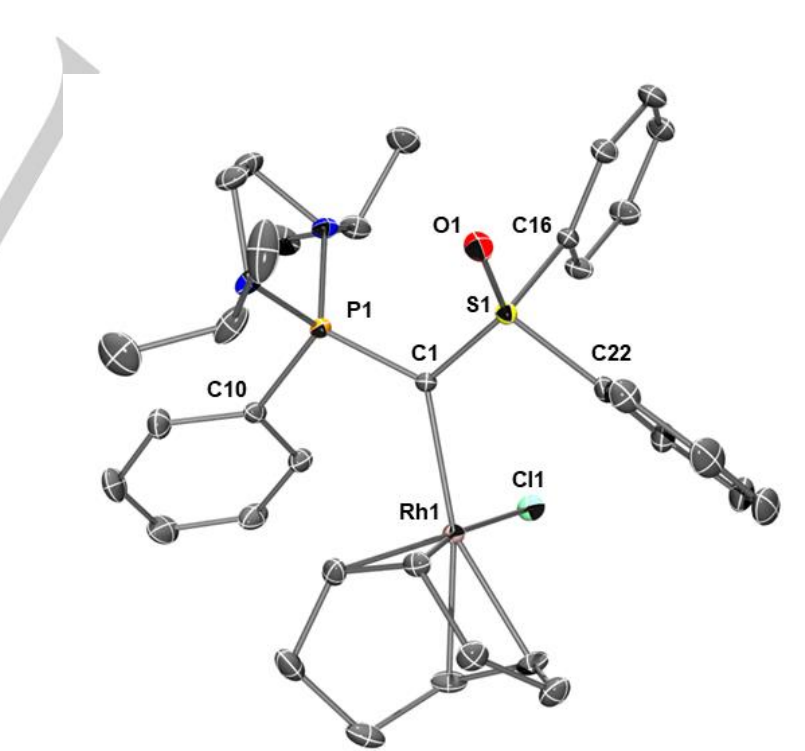

Figure 6. Molecular structure of 5. Thermal ellipsoids represent $30 \%$ probability. $\mathrm{H}$ atoms were omitted for clarity. Selected bond lengths $[\AA]$ and angles [ ${ }^{\circ}$ ]: S1-C1 1.6400(14), P1-C1 1.7070(14), C1-Rh1 2.1757(13), P1-C10 1.8144(14), S1-C16 1.7996(15), S1-C22 1.7928(15), O1-S1 1.4650(11), Rh1Cl1 2.4503(4), S1-C1-P1 114.36(8), P1-C1-Rh1 125.80(7), Rh1-C1S1 118.60(7). 


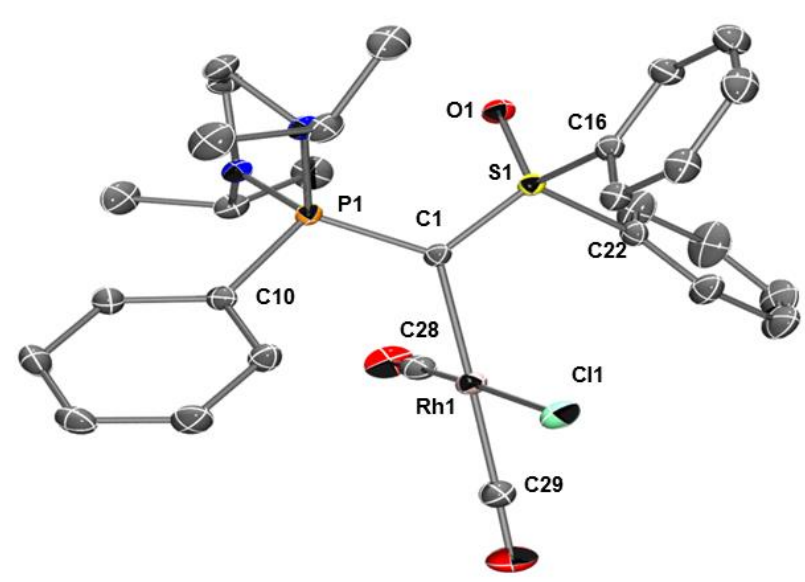

Figure 7. Molecular structure of 6 . Thermal ellipsoids represent $30 \%$ probability. $\mathrm{H}$ and disordered atoms and solvent $\left(\mathrm{C}_{6} \mathrm{D}_{6}\right)$ were omitted for clarity. Selected bond lengths $[\AA]$ and angles [ $\left.{ }^{\circ}\right]$ : S1-C1 1.654(2), P1-C1 1.709(2), C1Rh1 2.165(2), P1-C10 1.806(2), S1-C16 1.794(2), S1-C22 1.788(2), O1-S1 1.460(2), Rh1-Cl1 2.400(1), Rh1-C28 1.824(3), Rh1-C29 1.874(3), S1-C1

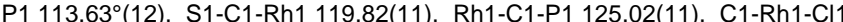
94.46(6), Cl1-Rh1-C29 85.06(8), C29-Rh1-C28 90.60(11), C28-Rh1-C1 89.95(9).

The IR spectrum of 6 shows the characteristic CO-stretching frequencies with an average value of $2016 \mathrm{~cm}^{-1}$, which is in the range of those observed for cyclic or acyclic bent allenes (2018 and $2014 \mathrm{~cm}^{-1}$ respectively). $\left.{ }^{[5 b}, \quad 9 b, \quad 9 c, \quad 27\right]$ Therefore, phosphine/sulfoxide carbone 2 appears to be stronger electrondonating ligand than classical NHCs $\left(2060-2036 \mathrm{~cm}^{-1}\right)$ but weaker compared to cyclic carbodiphosphoranes $\left(2001 \mathrm{~cm}^{-1}\right)$ (Figure 8). ${ }^{[9 a, 28]}$
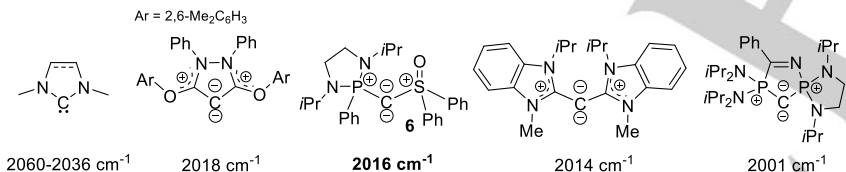

$2060-2036 \mathrm{~cm}^{-1} \quad 2018 \mathrm{~cm}^{-1} \quad 2016 \mathrm{~cm}^{-1}$ $2014 \mathrm{~cm}^{-1}$ $2001 \mathrm{~cm}^{-1}$

Figure 8. Comparison of $\operatorname{vav}(\mathrm{CO})$ stretching frequencies of cis$\left[\mathrm{RhCl}(\mathrm{CO})_{2} \mathrm{~L}\right]$ complexes.

In summary, we have successfully synthesized and characterized an original phosphine/sulfoxide-carbone 2 easily obtained from the corresponding cationic salt. As expected, the introduction of the sulfoxide ligand dramatically enhances the stability of this new carbon(0) complex. In comparison with previous phosphine/sulfide-carbone model, 2 exhibits an excellent coordination ability and thus allowed the stabilization and characterization of several organometallic complexes [Au(I), $\mathrm{Rh}(\mathrm{I})]$. The carbone character of $\mathbf{2}$ was demonstrated by the isolation of neutral gem-aurated complex 4, establishing the ability of ligand $\mathbf{2}$ to act as a four-electron donor. Moreover, the electron-donating character of $\mathbf{2}$ is much stronger than that of $\mathrm{NHCs}$ and we can expect that the corresponding transition-metal complexes could exhibit interesting catalytic activities. Efforts are currently underway to extend the diversity of organometallic complexes and in order to test their catalytic activities.

\section{Acknowledgements}

This work was supported by the CNRS and the Universite de Toulouse, UPS. We would also like to thank CONACyT México 207613-FOIINS-France project and Conacyt-México for the Ph.D. grant extended to M.L-G. Financial support from the Spanish Ministry of Economy and Competitiveness (grant CTQ2016-77978-R) is acknowledged.

Keywords: $\operatorname{carbon}(0)$ complexes $\cdot$ phosphine $\cdot$ sulfoxide $\bullet$ ligand - $\sigma$-donor

[1] a) A. Igau, H. Grützmacher, A. Baceiredo, G. Bertrand, J. Am. Chem Soc. 1988, 110, 6463; b) A. J. Arduengo, R. L. Harlow, M. Kline, J. Am. Chem. Soc. 1991, 113, 361 .

[2] a) W. Kirmse, Carbene Chemistry, 2nd ed Academic Press, New York 1971; b) D. Bourissou, O. Guerret, F. P. Gabbai, G. Bertrand, Chem. Rev. 2000, 100, 39; c) Y. Canac, M. Soleilhavoup, S. Conejero, G. Bertrand, J. Organomet. Chem. 2004, 689, 3857; d) Reactive Intermediate Chemistry (Eds.: R. A. Moss, M. S. Platz, M. Jr Jones), Wiley, New York, 2004; e) J. Vignolle, X. Cattoën, D. Bourissou, Chem. Rev. 2009, 109, 3333; f) O. Schuster, L. Yang, H. G. Raubenheimer, M. Albrecht, Chem. Rev. 2009, 109, 3445.

[3] a) Carbene Chemistry: From Fleeting Intermediates to Powerfu Reagents (Ed.: G. Bertrand), Marcel Dekker, New York, 2002; b) S. P. Nolan, N-Heterocyclic Carbenes in Synthesis, Wiley-VCH, Weinheim, 2006; c) D. Martin, M. Melaimi, M. Soleilhavoup, G. Bertrand, Organometallics 2011, 30, 5304; d) F. Lavigne, E. Maerten, G. Alcaraz, N. Saffon-Merceron, A. Baceiredo, Chem. Eur. J. 2014, 20, 297.

[4] a) D. Enders, T. Balensiefer, Acc. Chem. Res. 2004, 37, 534; b) D. Enders, O. Niemeier, A. Henseler, Chem. Rev. 2007, 107, 5606; c) N. Marion, S. Diez-Gonzalez, S. P. Nolan, Angew. Chem. Int. Ed. 2007, 46, 2988; d) A. Grossmann, D. Enders, Angew. Chem. Int. Ed. 2012, 51, 314; e) P. Chauhan, D. Enders, Angew. Chem. Int. Ed. 2014, 53, 1485.

[5] a) F. Glorius in N-Heterocyclic Carbenes in Transition Metal Catalysis, Vol. 21 (Ed.: F. Glorius), Springer, Berlin, Heidelberg, 2006, p. 1; b) T. Kato, E. Maerten, A. Baceiredo in Transition Metal Complexes of Neutral $\eta^{1}$-Carbon Ligands, Vol. 30, XI ed. (Eds.: R. Chauvin, Y. Canac), Springer, Berlin, 2010, p. 131.

[6] F. Ramirez, N. B. Desai, B. Hansen, N. McKelvie, J. Am. Chem. Soc. 1961, 83, 3539

[7] a) R. Tonner, F. Öxler, B. Neumüller, W. Petz, G. Frenking, Angew. Chem. Int. Ed. 2006, 45, 8038; b) R. Tonner, F. Öxler, B. Neumüller, W. Petz, G. Frenking, Angew. Chem. Int. Ed. 2006, 45, 8038; c) R. Tonner G. Frenking, Angew. Chem. Int. Ed. 2007, 46, 8695; d) R. Tonner, G. Frenking, Chem. Eur. J. 2008, 14, 3260; e) R. Tonner, G. Frenking Chem. Eur. J. 2008, 14, 3273.

[8] a) T. Fujii, T. Ikeda, T. Mikami, T. Suzuki, T. Yoshimura, Angew.Chem Int. Ed. 2002, 41, 2576; b) M. Alcarazo, C. W. Lehmann, A. Anoop W.Thiel, A. Fürstner, Nat. Chem. 2009, 1, 295; c) N. Dellus, T. Kato, X Bagan, N. Saffon, V. Branchadell, A. Baceiredo, Angew.Chem.Int. Ed. 2010, 49, 6798; d) M. Alcarazo, Dalton Trans. 2011, 40, 1839; e) M. Alcarazo, K. Radkowski, G. Mehler, R. Goddard, A. Fürstner, Chem. Commun. 2013, 49, 3140; f) H. Schmidbaur, A. Schier, Angew.Chem. Int. Ed. 2013, 52, 176; g) T. Morosaki, T. Suzuki, W. W. Wang, S. Nagase, T. Fujii, Angew. Chem. Int. Ed. 2014, 53, 9569; h) T. Morosaki, W.-W. Wang, S. Nagase, T. Fujii, Chem. Eur. J. 2015, 21, 15405; i) W.C. Chen, J.-S. Shen, T. Juca, C.-J. Peng, Y.-H. Lin, Y.-P. Wang, W.-C. Shih, G. P. A. Yap, T.-G. Ong, Angew. Chem. Int. Ed. 2015, 54, 15207; 
j) C. Pranckevicius, L. Liu, G. Bertrand, D. W. Stephan, Angew. Chem. Int. Ed. 2016, 55, 5536; k) T. Troadec, T. Wasano, R. Lenk, A Baceiredo, N. Saffon-Merceron, D. Hashizume, Y. Saito, N. Nakata, V. Branchadell, T. Kato, Angew. Chem. Int. Ed. 2017, 56, 6891; For a highlights on carbon(0) complexes see O. Kaufhold, F. E. Hahn, Angew. Chem. Int. Ed. 2008, 47, 4057.

[9] a) S. Marrot, T. Kato, H. Gornitzka, A. Baceiredo, Angew. Chem. Int. Ed. 2006, 45, 2598; b) C. A. Dyker, V. Lavallo, B. Donnadieu, G. Bertrand Angew. Chem. Int. Ed. 2008, 47, 3206; c) A. Fürstner, M. Alcarazo, R. Goddard, C. W. Lehmann, Angew. Chem. Int. Ed. 2008, 47, 3210; d) V. Lavallo, C. A. Dyker, B. Donnadieu, G. Bertrand, Angew. Chem. Int. Ed. 2008, 47, 5411.

[10] For earlier work on bis-ylides and related species such as methandiides and yldiides see selected reviews and references therein: a) "Transition Metal Complexes of Neutral $\eta^{1}$-Carbon Ligands", In Top. Organomet. Chem. 2010; 30; Eds: R. Chauvin, Y. Canac, Springer, Berlin, Germany; b) M. Fustier-Boutignon, N. Mezailles, Top. Organomet. Chem. 2014, 47, 63; c) V. H. Gessner, J. Becker, K.-S. Feichtner, Eur. J. Inorg. Chem. 2015, 1841; d) L. T. Scharf, V. H. Gessner, Inorg Chem. 2017, 56, 8599.

[11] For hydroamination see : a) R. Corberan, S. Marrot, N. Dellus, N. Merceron-Saffon, T. Kato, E. Peris, A. Baceiredo, Organometallics 2009, 28, 326; b) M. J. Goldfogel, C. C. Roberts, S. J. Meek, J. Am Chem. Soc. 2014, 136, 6227

[12] For Heck and Suzuki coupling see : Y.-C. Hsu, J.-S. Shen, B.-C. Lin, W.-C. Chen, Y.-T. Chan, W.-M. Ching, G. P. A. Yap, C.-P. Hsu, T.-G. Ong, Angew. Chem. Int. Ed. 2015, 54, 2420.

[13] For hydroarylation of diene with $\mathrm{N}$-heterocycles see : a) C. C. Roberts, D. M. Matias, M. J. Goldfogel, S. J. Meek, J. Am. Chem. Soc. 2015 137, 6488; b) J. S. Marcum, C. C. Roberts, R. S. Manan, T. N Cervarich, S. J. Meek, J. Am. Chem. Soc. 2017, 139, 15580.

[14] For olefin metathesis see: A. L. Liberman-Martin, R. H. Grubss, Organometallics, 2017, 36, 4091.

[15] C. Pranckevicius, L. Fan, D. W. Stephan, J. Am. Chem. Soc. 2015, 137, 5582.

[16] B. Inés, M. Patil, J. Carreras, R. Goddard, W. Thiel, M. Alcarazo, Angew. Chem. Int. Ed. 2011, 50, 8400.

[17] W.-C. Chen, W.-C. Shih, T. Jurca, L. Zhao, D. M. Andrada, C.-J. Peng, C.-C. Chang, S.-K. Liu, Y.-P. Wang, Y.-S. Wen, G. P. A. Yap, C.-P. Hsu, G. Frenking, T.-G. Ong, J. Am. Chem. Soc. 2017, 139, 12830

[18] A. Garduno-Alva, R. Lenk, Y. Escudié, M. Lozano González, L. Bousquet, N. Saffon-Merceron, C. Alvarez Toledano, X. Bagan, V.
Branchadell, E. Maerten, A. Baceiredo, Eur. J. Inorg. Chem. 2017, 3494

[19] CCDC 1584802 (1), 1584803 (2), 1584804 (3), 1584805 (4), 1584806 (5) and 1584807 (6) contain the supplementary crystallographic data for this paper. These data can be obtained free of charge from The Cambridge Crystallographic Data Centre.

[20] a) L. Pauling, The Nature of the chemical Bond, 3rd Ed.; Ithaca, Cornell University Press, New York, 1960; b) O. I. Kolodiazhnyi in Phosphorus Ylides: Chemistry and Application in Organic Synthesis, Wiley- $\mathrm{VCH}$, Weinheim, 1999

[21] T. Morosaki, R. lijima, T. Suzuki, W.-W. Wang, S. Nagase, T. Fujii Chem. Eur. J. 2017, 23, 8694.

[22] Calculated at the $M 06-2 X / 6-311+G(d, p) / / M 06-2 X / 6-31 G(d)$ level of theory. Wiberg bond order increases for bonds that get shorter upon deprotonation and vice versa. See supporting information.

[23] a) H. Schmidbaur, O. Gasser, Angew. Chem. Int. Ed. 1976, 15, 502; b) J. Vicente, A. R. Singhal, P. G. Jones, Organometallics, 2002, 21, 5887.

[24] For C-Sulfoxonium bond length see: a) O. Knop, T. S. Cameron, P. K. Bakshi, A. Linden, S. P. Roe, Can. J. Chem. 1994, 72, 1870; b) J. M. Stoddard, K. J. Shea, Organometallics 2003, 22, 1124; c) G. Laus, V. Kahlenberg, K. Wurst, H. Schottenberger, N. Fischer, J. Stierstorfer, T. M. Klapötke, Crystals 2012, 2, 127; For C-phosphonium bond length see : a) A. H. Cowley, R. A. Kemp, J. G. Lasch, N. C. Norman, C. A Stewart, J. Am. Chem. Soc. 1983, 105, 7444; b) F. Boutonnet, M. Zablocka, A. Igau, J.-P. Majoral, B. Raynaud, J. Jaud, Chem.Commun 1993, 1866; c) F. Buß, P. Mehlmann, C. Mück-Lichtenfeld, K. Bergander, F. Dielmann, J. Am. Chem. Soc. 2016, 138, 1840.

[25] a) W. A. Herrmann; M. Elison, J. Fisher, C. Köcher, G. R. J. Artus Chem. Eur. J. 1996, 2, 772; b) D. Enders, H. Gielen, J. Runsink, K Breuer, S. Brode, K. Boehn, Eur. J. Inorg. Chem. 1998, 913; c) K. Denk, P. Sirsch, W. A. Herrmann, J. Organomet. Chem. 2002, 649, 219; d) M. Mayer, K. Wurst, K. H. Ongania, M. R. Buchmeiser, Chem. Eur. J. 2004, 10, 1256; e) C. Präsang, B. Donnadieu, G. Bertrand, J. Am. Chem. Soc. 2005, 127, 10182; f) D. Martin, A. Baceiredo, H. Gornitzka, W. W. Schoeller, G. Bertrand, Angew. Chem. Int. Ed. 2005, 44, 1700.

[26] Complex 6 was isolated as a mixture of $6: 1$ in a $8 / 2$ ratio (see Supp. Information)

[27] F. Lavigne, A. El Kazzi, Y. Escudié, E. Maerten, T. Kato, N. SaffonMerceron, V. Branchadell, F. P. Cossio, A. Baceiredo, Chem. Eur. J. 2014, 20, 12528.

[28] V. Lavallo, Y. Canac, A. DeHope, B. Donnadieu, B. Bertrand, Angew. Chem. Int. Ed. 2005, 44, 7236. 
Entry for the Table of Contents (Please choose one layout)

Layout 1:

\section{COMMUNICATION}

A stable phosphine/sulfoxide carbone was isolated and fully characterized by NMR spectroscopy and by X-Ray crystallography. This species exhibits excellent coordination ability and the corresponding Rh(I)-dicarbonyl complex indicates a strong nucleophilic character, in clear agreement with theoretical calculations.

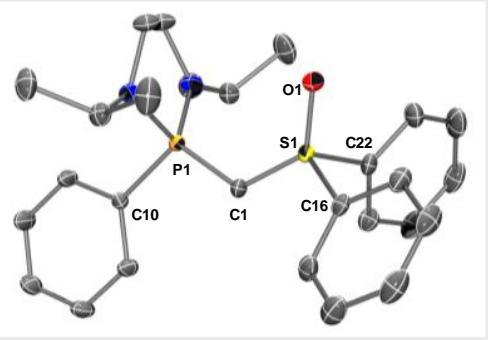

M. Lozano González, L. Bousquet, S. Hameury, N. Saffon-Merceron, C.

Alvarez Toledano, V. Branchadell, E. Maerten* and A. Baceiredo*

Page No. - Page No.

Phosphine/Sulfoxide-Supported

Carbon(0) Complex 